\title{
Some Thoughts on Massive Affordable Housing Schemes under the Pressure of Commodity Housing Inventory in China's Cities
}

\author{
Ling Xu \\ School of Business, Hubei University, Wuhan, China \\ Email: 3135868504@qq.com
}

How to cite this paper: $\mathrm{Xu}, \mathrm{L}$. (2017) Some Thoughts on Massive Affordable Housing Schemes under the Pressure of Commodity Housing Inventory in China's Cities. Open Access Library Journal, 4: e3722.

https://doi.org/10.4236/oalib.1103722

Received: June 8, 2017

Accepted: June 12, 2017

Published: June 15, 2017

Copyright $\odot 2017$ by author and Open Access Library Inc.

This work is licensed under the Creative Commons Attribution International License (CC BY 4.0).

http://creativecommons.org/licenses/by/4.0/

\section{(c) (i) Open Access}

\begin{abstract}
The scale of China's affordable housing construction is unprecedented in 12th Five-Year Plan, whether from the planning objectives, or the actual completion of present situation. However, under the increasing pressure of urban commercial housing inventory, it is urgently needed to carry out a reasonable co-ordination with urban housing supply side. Based on the review of the construction and development of affordable housing and commercial housing in 12th Five-Year Plan, this paper analyzes the relationship between them from the perspective of housing supply front in China's cities, and further tries to discuss about the implementation path of improvement and upgrade of affordable housing in the period of 13th Five-Year Plan.
\end{abstract}

\section{Subject Areas}

Social Issues and Public Policy

\section{Keywords}

Affordable Housing, Commodity Housing Inventory, Housing Problem, Housing Supply Front

\section{Introduction}

Since the establishment of new China, the perfection of the Urban Housing Security System of China and the construction of the government subsidized housing have become the important methods to solve the housing problem of the families with housing difficulties due to the medium and low income. The focal point for the major development objective of the Urban Housing Security System has also experienced the transformation from the public housing to the economically affordable houses, the low rent housing, public rental housing and 
shed modified house. At the beginning of the twelfth five-year, the central government made plans for the construction of the government subsidized housing of large scale [1]. However, in the meantime of basic completion for the objective of constructing the government subsidized housing of large scale nationwide at the end of the twelfth five-year, the inventory of the commercial housing in the cities of China has been climbing rapidly due to the slowdown of the speed for the economic development, the lack of reasonable planning for the development of the commercial housing, the development volume being too concentrated and the adjustment of the policy etc. The unsalable situation and vacancy of are more serious for the commercial housing in the medium and small cities in particular [2]. On the Central Economic Working Conference of 2016, "the elimination of inventory" was considered as the important task of the economic work in 2016, there is a new keynote nationwide with the regard to the adjustment of policy in the market of real estate [3]. Both the commercial housing and the government subsidized housing are the important components of the supply side for the urban housing, this article analyzes the relationship of the two on the base of review and carding for the general situation of the development and construction of both the government subsidized housing and the commercial housing during the twelfth five-year and tries to put forward the thinking and solution which are the coordination for the construction of the government subsidized housing and the elimination of inventory for the commercial housing and meditates for the further adjustment of the government subsidized housing by the face to the thirteenth five-year and the transformation and upgrading.

\section{The Development and General Situation of the Government Subsidized Housing}

i) The urban housing problems and the government subsidized housing

After the Chinese Economic Reform, the supply type of the urban housing in China has been gradually transforming from the physical distribution to the housing monetary distribution dominated by the market supply [4]. The market of real estate in China grows out of nothing and develops continuously. From the comparison of the data for the fifth and sixth population census, the proportion of purchase for the commercial housing by the Chinese citizens is raised from $7.98 \%$ in 2000 to $25.03 \%$ in 2010 [3]. With the development of the real estate market, the urban housing price, especially the housing price of metropolitans remains at a high level which generates the problem of affordability for the medium and low income families to purchase the housing. However, a certain housing condition for the citizens has been considered as the basic livelihood guarantee since the establishment of new China, and the Housing Guarantee System has been continuously improved in the process of reform and development for the housing security system. The physical guarantee of housing and the housing subsidies are the two most basic patterns in the structure of the housing guarantee system. While the government subsidized housing is the most important component in the physical housing guarantee [5]. Through the continuous 
development, it has been gradually formed as the government subsidized housing of property type with the representatives of economically affordable house, commercial housing with price ceilings, modified house at shanty towns and the security housing system of rent type with the representatives of low rent house and public rental housing. Through the continuous exploration and efforts of the central and local governments, in the meantime of solving or alleviating the housing problems for some of the medium and low income families under the pressure of high housing price, the government subsidized housing also plays the function of stabilizing the price of the commercial housing and expanding the consumption of housing [6].

ii) Review for the development of the government subsidized housing since the twelfth five-year

The construction for the government subsidized housing of large scale. According to the sorting of the statistical yearbook over the years, during the 10 years between 2000 and 2010, the accumulated number of the economically affordable houses built nationwide is 4.8254 million suits. While the central government put forward the target of government subsidized urban housing for 36 million suits by 2015 in the planning of housing security during the twelfth fiveyear in 2010. According to the statistics by the end of 2015, by the look of the government subsidized urban housing in the new constructions, the number of the government subsidized urban housing in the new constructions of 2011 during the twelfth five-year is 10.43 million suits (see Image 1), after that the average number of the government subsidized urban housing in the new constructions from 2012-2015 is about 7 million suits; the total volume in the new constructions of 5 years reaches 40.13 million suits. By the look of the scale for the government subsidized urban housing with the completion for the construc-

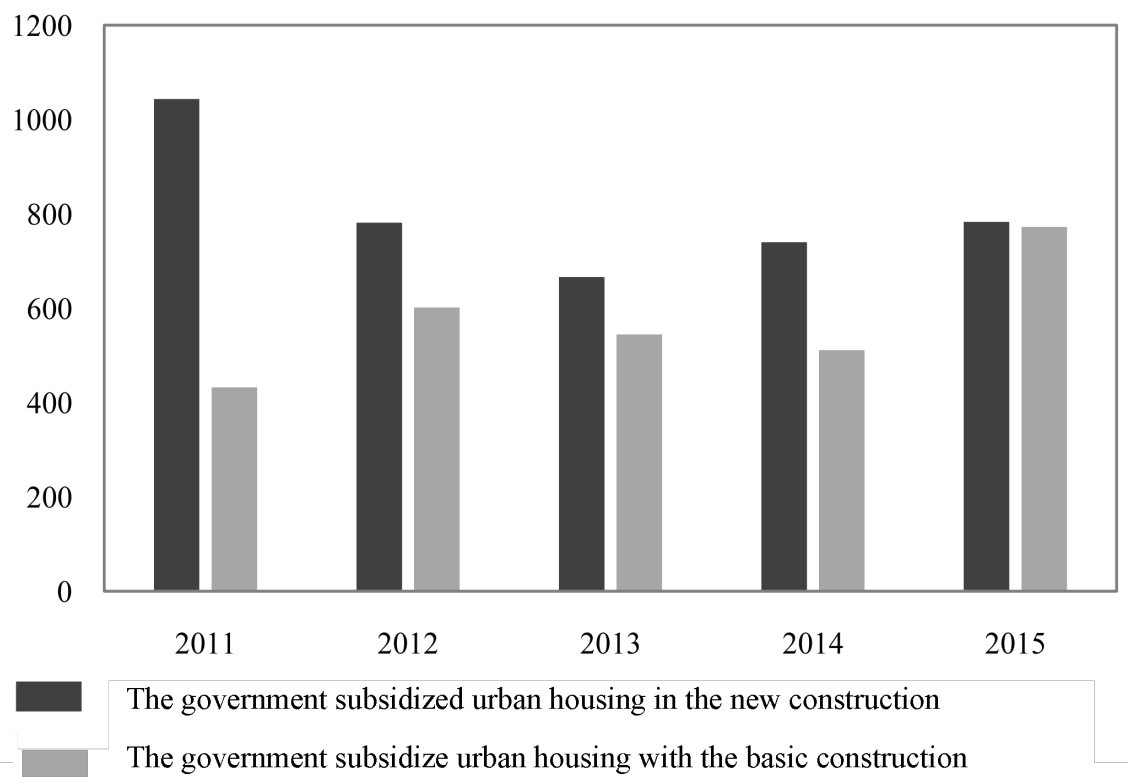

Image 1. The comparison of change for the areas of inventory at the respective levels of cities from 2011-2015. 
tion, the average number of the government subsidized urban housing with the completion for the construction from 2012-2015 is more than 5 million suits with the exception of 2001; the accumulated number of the government subsidized housing with the basic construction of 5 years reaches 28.6 million suits which is equal to the $71.27 \%$ of the volume for the new construction (see Table 1). During the eleventh five-year, the number of the government subsidized urban housing in the new constructions and the number of the government subsidized urban housing with the basic construction are 16.3 million suits and 11 million suits. Comparatively speaking, the construction scale of the government subsidized housing during the period of the twelfth five-year is about 2.5 times of that during the period of the eleventh five-year. Whether looking from the target in the planning or the actual situation of completion, the construction scale of the government subsidized urban housing in China during the period of the twelfth five-year is unprecedented.

\section{The Regional Difference for the Inventory of the Commercial Housing}

Through the summary and comparison for the data from the National Bureau of Statistics and the department of housing management at the respective areas, it is discovered that the differentiation of the inventory for the commercial housing in the first tier cities, second tier cities and third and fourth tier cities is apparent. First of all, the area for the inventory in first tier cities appear with the tendency of decrease in general, the pressure of inventory is comparatively low. Specifically speaking, the area for the inventory in the first tier cities is decreased from 35.97 million $\mathrm{m}^{2}$ to 29.10 million $\mathrm{m}^{2}$ during the period of 2011-2013 with the decreasing amplitude of $19.1 \%$; the area for the inventory is increased to $38.97 \mathrm{~m}^{2}$ from $2013-2014$ with an increase of $34 \%$; while the national policy is comparatively loose in 2015 , the area for the inventory experiences a decrease of small amplitude for $12.8 \%$ which is 34 million $\mathrm{m}^{2}$. Secondly, after 2013 , except the first tier cities experience the continuous decrease with small amplitude for the area of inventory, the rest cities continue to increase for the area of inventory, especially the third and fourth tier cities of which the area of inventory

Table 1. The situation for the construction of the government subsidized housing from 2011-2015.

\begin{tabular}{ccccccc}
\hline Year & 2011 & 2012 & 2013 & 2014 & 2015 & 小计 \\
\hline $\begin{array}{c}\text { The government subsidized urban } \\
\text { housing in the new construction } \\
\quad \text { (ten thousand suits) }\end{array}$ & 1043 & 781 & 666 & 740 & 783 & 4013 \\
$\begin{array}{c}\text { The government subsidize urban } \\
\text { housing with the basic construction } \\
\quad \text { (ten thousand suits) }\end{array}$ & 432 & 601 & 544 & 511 & 772 & 2860 \\
$\quad \begin{array}{c}\text { The completion rate (\%) } \\
\quad\end{array}$ & 41.42 & 76.95 & 81.68 & 69.05 & 98.60 & 71.27 \\
\hline
\end{tabular}

The material resource is gained from the sorting of the "Statistical Report on National Economy and Social Development" in 2012-2015 respectively. 
reaches 251 million $\mathrm{m}^{2}$ that exceeds the second tier cities of 212 million $\mathrm{m}^{2}$. Finally, the increase volume and the speed for the area of inventory at the third and fourth tier cities during the twelfth five-year is far over that of the first tier and second tier cities (see Image 2). Especially in 2014-2015, the area of inventory in the first tier and second tier cities start to decrease under the impact of the respected aspects such as the policy and the resources, while the area of inventory in the third and fourth tier cities increases in a more rapid way, it is 357 million $\mathrm{m}^{2}$ from 2013-2014 with an increase of $41.9 \%$; it is 476 million $\mathrm{m}^{2}$ in 2015 with an increase of $33.3 \%$. From this it can be seen that the inventory situation for the commercial housing in the third and fourth tier cities is more serious.

The material resource is gained by the summary for the data published by the respective departments of construction and management for the urban housing.

\section{Brief Summary and Thinking}

Looking at the development tendency of public housing across the world in future (the government subsidized housing in the western sense), no matter it is for a developed country or a developing country, housing is still one of the topics that needs to be considered first by the state with the regard to the affordability of the residents and the problem of benefit. The tendency of which the state interferes the housing market by means of public housing will continue. While the commonness of the residents to the desire of ownership for the housing, the contradiction between the scarcity of public housing and the problem of payment and the tendency of population aging will impact the development of public housing in future. This article selects the related indexes for the analysis of the relativity between the construction scale of the government subsidized housing and the inventory volume of the commercial housing during the period

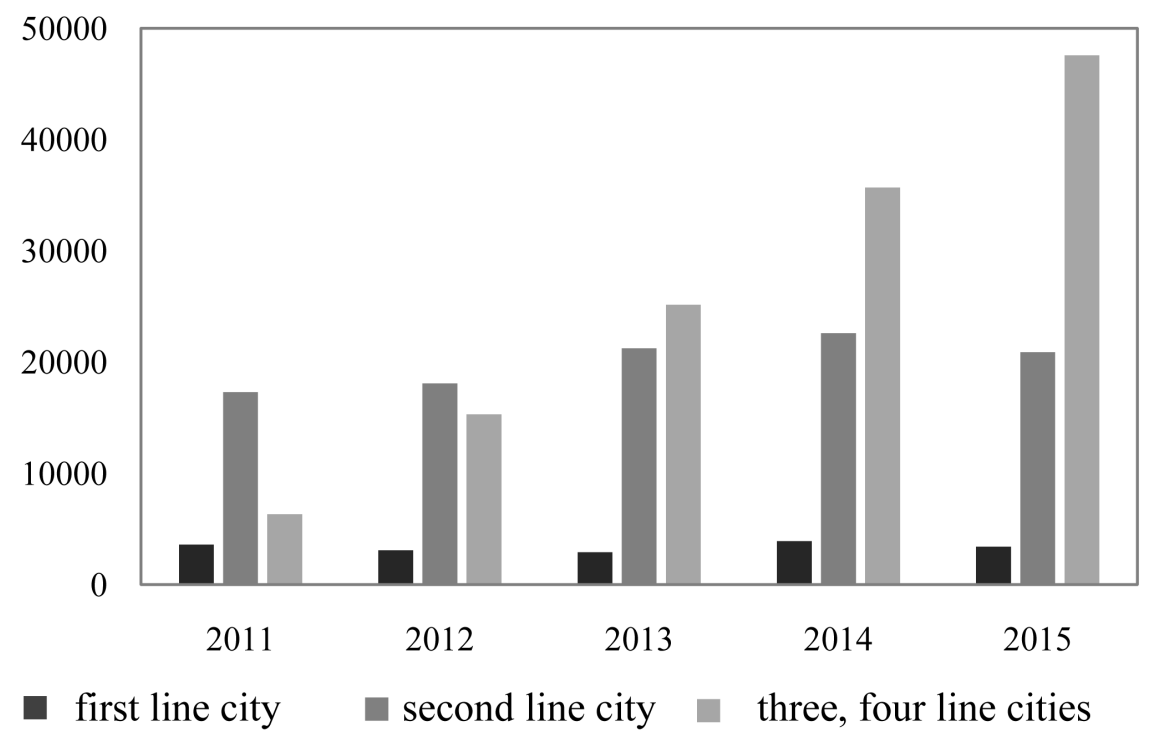

Image 2. The comparison of change for the area of inventory in the cities of respective levels from 2011-2015. 
of the twelfth five-year on the base of the general situation for the development of government subsidized housing during the period of twelfth five-year and the sorting for the construction, sales and inventory change of the commercial housing and explores the possibility of connection for the two and the three kinds of basic thinking and finally gets the following conclusion and thinking by the face to the tendency of development for the national economy during the thirteenth five-year.

1) Brief summary. The government subsidized urban housing in China experienced the development of straddle type during the period of the twelfth fiveyear, but it appeared more on the quality of large-scale construction. By the look at the target of construction for 36 million suits which was put forward at the beginning of the twelfth five-year. it may accommodate all the citizens in the Great Britain and Poland by 3 residents for each suit; The accumulated number of the government subsidized housing with the basic construction at the end of the twelfth five-year reaches 28.6 million suits which may accommodate all the citizens in Germany; While the 40.13 million suits in the accumulated construction may accommodate 120 million residents after the complete construction which is equal to the number of the residents in Japan. The inventory volume of the commercial housing during the period of the twelfth five-year gradually increases and the differentiation is dramatic for different cities. On one aspect, by the look at the tendency of slowdown for the economic development, the shrinkage for the local fiscal funds and the total supply volume of the urban housing, we have basically said goodbye to the time of "shortage", how to keep the inventory volume of the commercial houses is one of the key points of the economic work; On the other aspect, with the gradual increase for the income of the citizens, the demand of the citizens for the housing also appears with diversification and multiple layers, the tendency is that the new immigrants of cities on the rigid demand for the housing will co-exist with the demand of home improvements for those who already have housing [7]. Innovation integrates the elimination of inventory for the commercial housing and the construction of the government subsidized housing organically which opens up the channel of connection between the government subsidized housing and the elimination of inventory for the commercial housing, it may achieve the target of win-win with both the guarantee for the livelihood and the elimination of inventory for the commercial housing.

2) Thinking the perfection for the policy of the government subsidized housing is not for the requirement and ability for the construction of housing. By the look at the demand side of urban housing, not only do we need to know the quantity of effective demand, we also need to know the characteristics and difference of quality demanded by the medium and low income families with difficulties of housing. By the look at the supply side of urban housing, not only do we need to explore the physical housing guarantee, we also need to explore more types of guarantee, and think for the solution of urban housing security under the housing framework of the whole city; How to achieve the effective match 
between the supply and demand of the urban housing, it requires the related departments of the central and local governments to continuously explore on how to provide the government subsidized urban housing to conduct the scientific decision and the level of accurate management from the theory and practice. While in this process, due to the big difference of the respective regions, we should practically integrate the national conditions and the local conditions for the flexible and diversified methods of achievement. Of which the important directions for the exploration include: the transformation from the "supplement of bricks" to the "supplement of human heads", we should complete the modification and accommodation of the shanty town and the sales for the stock of commercial housing by the currency allowances and the purchase guidance based on the diversified demand of the residents and achieve the transformation upgrade from the development method of pursuit for the target of the total quantity for the government subsidized housing in a sports type to the diversified, flexible and scientific development method with the focus on quality, outstanding structure.

\section{References}

[1] Wang, Y.L. and Gao, L. (2016) Research on the Method of Eliminating the Inventory of Real Estate. The Town and Country Construction, 1, 18-20.

[2] Gao, J.H. (2016) Speed up the Progress for the Elimination of Inventory, Seek for the Rebalance in the Market of Real Estate. China Development Observation, 1, 1315.

[3] Zhang, Z., Chen, K.L., Tu, S. and Liu, Y.Z. (2014) The Composition of Resources for the Housing of the Chinese Citizens and the Interprovincial Difference-Based on the Analysis on the Data of "the Fifth Population Census" and "the Sixth Population Census. World Geographic Research, 3, 52-63.

[4] Zhu, Y.P. (2008) Analysis on the Policy for the Housing Guarantee in China-From the Perspective of Social Policy. Public Administration Review, 4, 76-94.

[5] Ye, X.S. and Huang, L.J. (2013) The Construction for the System of the Government Subsidized Housing in China under the Guidance of Justice and Efficiency. The Urban Development Studies, 2, 35-39.

[6] Wen, L.F. (2009) The Current Status of the Government Subsidized Housing in China. Beijing University-Research Achievements of Lincoln Research Institute, $11,36-45$.

[7] Zhang, Z., Zhang, Y.J., Chen, K.L. and Zhou, M. (2015) The Development, Characteristics of the Commensalism Social Communities in the United States and Its Inspiration. Chinese Soft Science, 11, 50-58. 
Submit or recommend next manuscript to OALib Journal and we will provide best service for you:

- Publication frequency: Monthly

- 9 subject areas of science, technology and medicine

- Fair and rigorous peer-review system

- Fast publication process

- Article promotion in various social networking sites (LinkedIn, Facebook, Twitter, etc.)

- Maximum dissemination of your research work

Submit Your Paper Online: Click Here to Submit

Or Contact service@oalib.com 